Исследовательская деятельность формирует положительную мотивацию студентов, будущих педагогов, к изучению математики, является необходимой составляющей их профессии. Учитель математики и информатики несомненно должен хорошо разбираться в своем предмете и компьютерных технологиях, стремиться развиваться и самообразовываться, чтобы быть интересным своим ученикам, чтобы замотивировать их на приобретение новых знаний, на желание учиться, чтобы уровень математического образования неуклонно повышался.

$$
* * *
$$

1. Ипполитова Н.В., Стерхова Н.С. Анализ понятия «Исследовательская деятельность студентов педагогического вуза» // Дискуссия. 2016. № 8(71). С. 112-120.

2. Валеева О.А., Железовская Г.И. Учебно-исследовательская деятельность как форма учебной работы // Вестник высшей школы. 2016. № 6. С. 53-56.

3. Ефанова Л. Д. Самостоятельная работа и самостоятельность студентов в вузе // Научнометодический электронный журнал «Концепт». - 2016. - T. 15. - C. 431-435. - URL: http://ekoncept.ru/2016/86989.htm. (дата обращения: 29.04.2021)

4. Кириллов А.А. Пределы. Издательство «Наука». Главная редакция физико-математической литературы, Москва, 1973, 96 стр. с илл.

\title{
Кильметова Р.Р., Климатов Х.Г. \\ Риск-ориентированный подход при проведении выездных налоговых проверок: правовая основа и практика применения
}

ФГБОУ ВО «СОГУ им. К.Л.Хетагурова»

(Россия, Владикавказ)

doi: $10.18411 / \mathrm{j}-06-2021-177$

\section{Аннотация}

В данной статье исследуются особенности специфики планирования выездных налоговых проверок с использованием риск-ориентированного подхода оценки налогоплательщиков. Изучаются результаты внедрения данного подхода на современном этапе.

Ключевые слова: налоговое право, налоговый контроль, рискориентированный подход, налоговое администрирование, выездная налоговая проверка, налоговое правонарушение.

\section{Abstract}

This article deals with the specifics of planning onsite tax audits using risk-based approach to assessing taxpayers. The results of the implementation of this approach at the present stage are studied.

Keywords: tax law, fiscal law, risk-based approach, the tax administration, onsite tax audit, tax offences.

Налоговая политика государства создается и осуществляется из необходимости создания и стимулирования положительных структурных изменений в экономике страны, снижения налоговой нагрузки не только с населения государства (физические лица), но и частных предприятий (юридические лица), а также для повышения эффективности налогового контроля.

Одним из важнейших условий эффективного функционирования налоговой системы и экономики государства является качественное налоговое администрирование. В свою очередь, налоговое администрирование неразрывно связано с налоговым контролем, целью которого является обеспечение своевременного и полного поступления налогов, взносов и других обязательных платежей в бюджет, а 
также достижения высокого уровня налоговой дисциплины и финансовой грамотности налогоплательщиков [1].

Из практики налогового контроля сложилось так, что наиболее эффективной формой налогового контроля являются выездные налоговые проверки. Данная форма налогового контроля имеет определенные задачи, которые и выступают конечной целью при осуществлении данной формы контроля, а именно:

- $\quad$ выявление и пресечение нарушений действующего законодательства о налогах и сборах;

- предупреждение налоговых правонарушений [2].

Для решения указанных задач и достижения поставленных выше целей, законодательными и исполнительными органами власти была подготовлена Концепция системы планирования выездных налоговых проверок, которая предусматривает создание системы отбора объектов для проведения выездных налоговых проверок [3].

Риск-ориентированный подход при налоговом администрировании впервые был затронут именно в данной концепции.

Согласно данной Концепции, основным критерием для отбора лиц (налогоплательщиков) для дальнейшего проведения выездной налоговой проверки является риск совершения налогового правонарушения. Следует также заметить, что до принятия Концепции, информация о критериях отбора лиц для данной формы налогового контроля была строго конфиденциальной, т.е. являлась сугубо внутренней конфиденциальной процедурой надзорного органа.

Под внутренней информацией понимается информация о налогоплательщиках, которая была получена налоговыми органами в процессе выполнения возложенных на них функции и полномочий. В свою очередь, к информации из внешних источников относится информация, которая была получена налоговыми органами при осуществлении налогового контроля от государственных и муниципальных органов, а также иная информация, которая находится в свободном доступе.

Для построения определенной стабильной системы по отбору объектов для последующего проведения выездной налоговой проверки, Концепцией был предусмотрен алгоритм отбора. Данный алгоритм предлагает осуществить полный и всесторонний анализе всей доступной информации, которой располагает налоговые органы. В последующем на основе полученных данных определяется степень и "зоны риска" совершения налоговых правонарушений.

Для отбора налогоплательщиков проводится предварительный многоуровневый анализ финансово-хозяйственной деятельности налогоплательщика, который состоит из:

- анализа сумм исчисленных налоговых платежей, а также их динамика за определенный промежуток времени, на основе которых возможно выявить налогоплательщиков, у которых уменьшаются суммы начислений налоговых платежей;

- анализа сумм, уплаченных налоговых платежей и их динамика во временном промежутке по каждому типу и/или виду налога с целью полноты и своевременности перечисления налоговых платежей;

- анализа показателей бухгалтерской и/или налоговой отчетности налогоплательщиков, в которой содержаться существенные отклонения показателей финансово-хозяйственной деятельности текущего отчетного периода от базисных или же отклонения от среднестатистических показателей отчетности по аналогичным отраслям деятельности и/или аналогичных экономических субъектов за определенный промежуток времени. 
- анализа факторов и оснований, которые влияют на формирование налоговой базы [2].

При включении в план выездных налоговых проверок приоритет отдается налогоплательщикам, о которых имеются сведенья о совершении налогового правонарушения, а также данные, свидетельствующие о его возможном недобросовестном (неправомерном) поведении.

Помимо указанных критериев оценки рисков налогоплательщика в налоговом органе, существуют критерии для самостоятельной оценки риска, которые доступны в личном кабинете налогоплательщика:

- $\quad$ расчет налоговой нагрузки и ее сравнении со средними показателями экономических хозяйствующих субъектов по виду экономической деятельности;

- $\quad$ занижение прибыли или отражение убытков как в бухгалтерской, так и в налоговой отчетности на протяжении нескольких анализируемых периодов;

- отражение значительной величины (доли) вычетов по налогу на добавленную стоимость от суммы начисленного налога;

- выплата сотрудникам заработной платы через «белые конверты», иными словами, «черная» заработная плата. Несоразмерность «белой» заработной платы сотрудников со средне отравляемыми показателями;

- осуществление деятельности с рентабельностью ниже среднеотраслевой или в сравнении с другими хозяйствующими субъектами;

- ведение финансово-хозяйственной деятельности с высокими налоговыми рисками.

Говоря о риск-ориентированном подходе, нельзя не упомянуть важность в проведении различий между понятиями «результативность» и «эффективность». Так, под эффективностью данного подхода стоит понимать стоимостное выражение дополнительных начислений (включая налоговые санкции и пени) на частное количество выездных налоговых проверок, а под результативностью - соотношения количество выездных проверок, в результате которых были выявлены налоговые правонарушения, к общему количеству таких выездных проверок [4].

Статистические данные о количестве выездных налоговых проверок и их результативности в 2007-2018 г2.

\begin{tabular}{|c|c|c|c|c|c|c|c|c|c|c|c|c|}
\hline Показатель & $\hat{8}$ & $\stackrel{\infty}{\stackrel{\infty}{8}}$ & 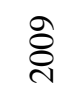 & 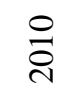 & $\overrightarrow{\bar{\sigma}}$ & $\frac{N}{\stackrel{d}{d}}$ & $\frac{m}{\stackrel{n}{\sigma}}$ & $\stackrel{\vec{d}}{\stackrel{\nabla}{*}}$ & $\frac{n}{\stackrel{n}{d}}$ & $\frac{0}{\stackrel{i}{d}}$ & $\stackrel{\sqrt{8}}{\text { d }}$ & $\stackrel{\infty}{\underset{\sim}{\sigma}}$ \\
\hline $\begin{array}{l}\text { Количество } \\
\text { выездных } \\
\text { налоговых } \\
\text { проверок, тыс. } \\
\text { ед. }\end{array}$ & 105,8 & 87,9 & 85,4 & 75,5 & 67,4 & 58,1 & 41,3 & 35,8 & 30,7 & 26 & 20,2 & 14,2 \\
\hline $\begin{array}{l}\text { Охват выездных } \\
\text { налоговых } \\
\text { проверок, в \% }\end{array}$ & 1,3 & 0,98 & 0,91 & 0,8 & 0,7 & 0,59 & 0,48 & 0,42 & 0,36 & 0,31 & н/д & \\
\hline $\begin{array}{l}\text { Результативност } \\
\text { ь выездных } \\
\text { налоговых } \\
\text { проверок, в \% }\end{array}$ & 96,9 & 98,7 & 99,2 & 99 & 98,9 & 99,1 & 98,8 & 98,8 & 99 & 99,1 & 98,1 & 97,2 \\
\hline $\begin{array}{l}\text { Доначислено на } \\
\text { одну проверку, } \\
\text { млн. руб. }\end{array}$ & 2,7 & 3,5 & 4,2 & 4,5 & 4,3 & 5,6 & 6,9 & 8,2 & 8,8 & 13,7 & 15,4 & 21,7 \\
\hline
\end{tabular}


Как видно из данной таблицы, начиная с года внедрения Концепции, количественные и качественные показатели стремятся к реальному максимальному значению. Так, из приведенных данных за анализируемый период, следует, что количество выездных налоговых проверок сократилось более чем в 19 раз - с 105,8 тыс. до 20,2 тыс. в год. Возможно предположить, что будет происходить дальнейшее уменьшение. Но возникает вопрос, до какого уровня и где будет точка перегиба с точки зрения связи результативности и эффективности. Из приведенных данных можно понять, что результативность данной формы контроля достигла своего предела в 2008 году и составила 98,7 \% и по настоящее время в среднем составляет 98,9 \% в год со среднеквадратическим отклонением 0,3. Также с каждым годом растет стоимостное значение доначислении на одну выездную проверку. На сегодняшний день по сравнению с годом начала Концепции доначисления выросли в 5,7 раза, или с 2,7 млн руб. до 15,4 млн. руб.

Риск-ориентированный подход позволяет повысить эффективность работы налоговых органов путем детального анализа налогоплательщиков, которые попали под определенные критерии проверяемого органа. На мой взгляд, одним из основных таких критериев является прибыль организации, так как цель создания коммерческой организации - получение и максимизация прибыли от своей основной деятельности. И если налогоплательщик недополучает данный финансовый результат, то возникает вопрос: зачем и с какой целью налогоплательщик осуществляет свою деятельность? Таким образом, организации, которые добросовестно и своевременно начисляют и уплачивают налоги, взносы и другие платежи со свой деятельности, автоматически отсеиваются из последующей аналитической выборки [5].

Стоит отметить, что при проведении риск-ориентированного подхода уделяется внимание связи между налогами, которые начисляются и уплачиваются налогоплательщиком, так как можно сказать, что все платежи налогоплательщика в пользу бюджета между собой связаны, и при уменьшении одного их них происходит косвенная или прямая корректировка других, а также и финансового результата налогоплательщика. При данном изменении налоговый орган начинает подробно анализировать, в связи с чем произошли данные изменения, и основания данных изменений.

Из всего вышеизложенного можно понять, что применение рискориентированного подхода налоговой службой выгодно как субъектам предпринимательской деятельности (добросовестные налогоплательщики автоматический исключаются из потенциальных претендентов на проведение выездной налоговой проверки), так и непосредственно самой налоговой службе (за счет уменьшения количества выездных налоговых проверок уменьшается нагрузка на налоговые органы, в связи с чем повышается эффективность налогового администрирования). Можно сказать, что риск-ориентированный подход является одной из самых актуальных мер налогового администрирования, который улучшает эффективность налоговых органов, позволяет им не только снизить бюрократическую нагрузку с налоговых органов, но и помогает в повышении уровня налоговой культуры населения РФ.

$$
* * *
$$

1. Приказ ФНС России от 30.05.2007 № ММ-3- 06/333@ (ред. от 10.05.2012) «Об утверждении Концепции системы планирования выездных налоговых проверок». [Электронный ресурс]. Доступ из справ.-правовой системы «КонсультантПлюс».

2. Новоселов К.В. Перспективы развития риск-менеджмента в налоговой сфере/ К.В. Новоселов // Экономика. Налоги. Право. - 2017. - № 3. - С. 29-38.

3. Соловьев А.И. Риск-ориентированный подход в системе государственного контроля и надзора в налоговой сфере / А.И. Соловьев // Экономика. Налоги. Право. - 2017. - № 3. - С. 139-146.

4. Артеменко Г.А. Применение риск-ориентированного подхода в методике налогового контроля // Вопросы регулирования экономики, 2011. - Том 2, № 2. - С.84-96.

5. Дадашев А.З., Лобанов А.В. Налоговое администрирование в Российской Федерации. М.: Книжный мир, 2012. . - 343 с. 